\title{
Cultura das séries: forma, contexto e consumo de ficção seriada na contemporaneidade
}

\author{
Marcel Vieira Barreto Silva
}

Resumo: Nos últimos anos aumentou o interesse acadêmico em torno das séries de televisão, especialmente - mas não somente -, as de origem norte-americana. Há toda uma literatura recente que avalia a presença das séries de TV em diversas matrizes nacionais (EUA, Itália, França, Reino Unido, etc.), analisando a produção, circulação e recepção dos programas. Neste artigo, vamos propor a existência de uma cultura das séries, a partir de três condições centrais: a sofisticação das formas narrativas, o contexto tecnológico que permite uma ampla circulação digital (online ou não) e os novos modos de consumo, participação e crítica textual. Com isso, as séries fomentam interesses que não se restringem ao envolvimento de comunidades de fãs com obras específicas, mas também indicam a formação de um repertório histórico em torno desses programas, de uma telefilia transnacional, de uma cultura das séries.

Palavras-Chave: cultura das séries; ficção seriada; televisão contemporânea.

Abstract: TV serial culture: format, context and consumption of serial fiction today - In recent years, the academic community has shown increasing interest in television series, particularly albeit not exclusively - in American TV series. There is a recent body of works that evaluate the presence of TV series in different national backgrounds (USA, Italy, France, UK, etc.), analyzing the production, circulation and reception of these programs. In this paper, we suggest the existence of a TV series culture, based on three conditions: the sophistication of the narrative formats, the technological context that allows for widespread digital circulation (on or offline), and the new modes of consumption, participation and textual criticism. As such, TV series stimulate interest that goes beyond fandom engagement with specific programs to encompass the development of a historical repertoire of these shows, a transnational telephilia, a TV series culture.

Keywords: TV series culture; serial fiction; contemporary television. 


\section{Introdução}

O aplicativo TV Shows, ${ }^{1}$ desenvolvido pelo espanhol Victor Pimentel para computadores Apple, funciona da seguinte maneira: a partir de uma lista de todos os programas seriados em exibição na televisão americana, o usuário seleciona aqueles que acompanha e, a cada episódio novo disponibilizado na rede, o aplicativo baixa automaticamente, via torrent, para o computador. Com um Apple TV, aparelho que reproduz em televisores de alta definição, sons e imagens via wi-fi, pode-se lançar o episódio baixado do computador para a televisão e assistir o programa em seu "habitat natural".

Fora isso, pode-se queimar um DVD ou mesmo lançar, via USB, diretamente no televisor. Apesar dessa e de outras novas possibilidades de consumo de séries de tevê, a transição da televisão para internet é algo que, pelo menos ainda, está longe de ser um processo consolidado. Os sistemas de banda larga não possuem, até o momento, capacidade tecnológica de superar a transmissão de radiofrequência por satélite, ou a transmissão via cabo, ainda mais para uma programação contínua em alta qualidade.

Uma banda larga ubíqua e a preço acessível permitiria que a televisão na internet pudesse rivalizar com a distribuição tradicional via satélite ou a cabo. No entanto, a televisão na internet, se usada desse modo por milhões de usuários, iria requerer uma enorme largura de banda para transferência de dados (GERBARG e NOAM, 2004, p. xxii).

No caso brasileiro, uma banda larga abrangente em nível nacional é ainda um sonho distante - a realidade concreta continua dominada pela televisão aberta e sua meia dúzia de canais distribuídos de norte a sul -, embora as TVs por assinatura venham nos últimos anos se popularizando, estamos longe de uma oferta mais ampla, dos pacotes mais básicos ou dos canais premium. Segundo dados oficiais da Anatel, ${ }^{2}$ o número total de assinantes no Brasil é de pouco mais de dezesseis milhões, o que equivale a uma densidade por domicílio de 28,1\%. Nos Estados Unidos, em torno de 43\% dos domicílios possui serviço de TV por assinatura, ${ }^{3}$ o que representa 56 milhões de assinantes.

Além disso, enquanto o número de assinantes de TV a cabo nos Estados Unidos vem diminuindo - numa média de um milhão a cada ano - os números dos serviços de video on demand (VOD) só aumentam. Em meados do ano passado, o Hulu Plus alcançou a marca de dois milhões de assinantes, enquanto o Netflix, maior e mais internacionalizado desses serviços, já alcançou quase 30 milhões de assinantes, dos quais 25 milhões estão nos Estados Unidos, e o restante nos demais países onde o serviço é oferecido, ${ }^{4}$ incluindo o Brasil. Boa parte do que é disponibilizado para streaming nesses serviços são programas

Disponível em: <http://tvshowsapp.com/>. Acesso em: jul. 2013.

Disponível em: <http://www.anatel.gov.br/hotsites/conheca_Brasil_SATVA/default.asp>. Acesso em: jul. 2013.

3 Disponível em: <http://www.ncta.com/Statistics.aspx>. Acesso em: jul. 2013.

4 Disponível em: <http://finance.yahoo.com/news/numbers-netflix-subscribers-205626248--finance.html>.

Acesso em: jul. 2013 
de televisão - a outra parte, obviamente, é de filmes -, e não apenas séries, mas também programas esportivos, reality shows, documentários, programas infantis e de entrevista.

O cenário atual, portanto, é de ampliação das formas de produção e consumo audiovisual, e embora a TV ainda esteja consolidada no modelo tecnológico de transmissão de sinal, o que implica uma experiência dominantemente nacional e em fluxo, o que chamamos aqui de cultura das séries é resultado dessas novas dinâmicas espectatoriais em torno das séries de televisão, destacadamente, as de matriz norte-americana.

Para entender a complexidade desse fenômeno, estamos aqui propondo três condições centrais que se consubstanciaram, nas duas últimas décadas, para promover esse panorama em que as séries ocupam lugar destacado dentro e fora dos modelos tradicionais de televisão: a primeira condição é a que chamamos de forma, e está ligada tanto ao desenvolvimento de novos modelos narrativos, quanto à permanência e à reconfiguração de modelos clássicos, ligados a gêneros estabelecidos como a sitcom, o melodrama e o policial.

A segunda condição está relacionada ao contexto tecnológico em torno do digital e da internet, que impulsionou a circulação das séries em nível global, para além do modelo tradicional de circulação televisiva. A terceira condição se refere ao consumo desses programas, seja na dimensão espectatorial do público, através de comunidades de fãs e de estratégias de engajamento, seja na criação de espaços noticiosos e críticos, vinculados ou não a veículos oficiais de comunicação como grandes jornais e revistas, focados nas séries de televisão.

Essas três condições buscam reunir o movimento cultural mais amplo em torno desses programas, dentro das particularidades dos contextos específicos de produção. Nosso objetivo adiante, neste artigo, é dissertar mais propriamente sobre cada uma dessas condições, apontando os principais debates teóricos sobre o tema na atualidade, a partir de exemplos concretos. Queremos, sobretudo, indicar elementos conceituais que possam nos ajudar a entender o fenômeno da produção e da circulação das séries de TV na contemporaneidade, a partir da evidência cultural de sua presença nas diferentes práticas de consumo televisivo, em escala transnacional.

\section{Formas narrativas: a premência da complexidade e a consagração do escritor/produtor}

Deu na Folha de São Paulo: ${ }^{5}$ a sofisticação do texto é um dos motivos - senão o artisticamente mais relevante - que garante o período de bonança que caracteriza as séries de televisão contemporâneas nos Estados Unidos. O argumento apresentado pela autora da matéria é que o ponto crucial desse momento seria o roteiro, capaz de fugir dos clichês e das formas narrativas consagradas, que Hollywood insiste em repetir ano a ano nos cinemas.

5 Disponível em: <http://www1.folha.uol.com.br/ilustrada/1197187-texto-sofisticado-sustenta-bonanca-das-series. shtml>. Acesso em: maio 2013. 
A partir disso, constata-se a migração de roteiristas, diretores e atores do cinema mainstream hollywoodiano para a televisão, movimento que, nos últimos anos, acrescentou às séries uma marca distintiva de qualidade (no melhor sentido bourdieusiano) que só o cinema poderia oferecer. O discurso que se constrói é o seguinte: ao vermos, nos créditos de Boardwalk Empire o nome de Martin Scorcese como produtor executivo, estamos garantindo ao programa uma marca de qualidade única, via transferência direta do prestígio do premiado diretor para a série da $\mathrm{HBO}$.

Esquece-se, com isso, o óbvio: a figura central de Boardwalk Empire não é Scorcese que até dirige o episódio piloto -, mas Terence Winter, o escritor/produtor. Pearson (2005) argumenta que a emergência da figura do escritor/produtor é uma das características cruciais desse processo. O escritor/produtor (também conhecido como showrunner) é o centro criativo do programa, responsável pela estrutura narrativa e pelo modo de encenação, mesmo em esquemas de produção mais amplos, com equipes variadas no roteiro e na direção.

É, portanto, o escritor/produtor que garante a unidade de sentido de um programa, seja pela supervisão do processo de escritura dos episódios, seja pelo estabelecimento de um padrão de encenação que garante replicação - lembrando o termo de Calabrese (1984) -, sem repetir clichês. A atenção ao escritor/produtor começou com o papel que Steven Bochco desempenhava na célebre Hill Street Blues, ainda no período chamado de "classical network system" (Hilmes, 2002), em que a TV norte-americana era dominada pelas três grandes redes (ABC, CBS e NBC).

A série surge e acaba definindo o momento de transformação do panorama televisivo nos anos 1980. Com a quebra da hegemonia das três grandes redes, a progressiva inserção da TV a cabo nos domicílios e a mudança no paradigma publicitário, que passa a pensar os programas não apenas como obras transversais que deviam interessar ao maior número de espectadores, mas como obras específicas, endereçadas a determinados públicos, com suas próprias características e interesses de consumo.

No caso das séries de televisão, é inegável que a figura do escritor/produtor carrega um valor distintivo análogo ao do diretor de cinema na crítica cinematográfica, que se manifesta nas marcas paratextuais publicitárias em torno dos programas (trailers, promos, entrevistas, etc.). Nas últimas décadas, nomes como David Chase, Joss Whedon, Aaron Sorkin, Allan Ball, Vince Gilligan, Matthew Weiner, J.J. Abrams, David Crane, Larry David, Tina Fey, Seth MacFarlane e Rick Gervais passaram a ser usualmente encontrados em comentários críticos sobre a excelência das séries de TV, capazes de mobilizar o interesse do público para obras diferentes do mesmo autor.

Dentro de um circuito crítico, que atribui relevância artística para as séries, a definição de uma marca autoral, como índice valorativo, ajuda a garantir o investimento em obras mais radicais narrativamente. Nesse contexto, a televisão segmentada passa a ser o lugar por excelência das séries "complexas" - para lembrar a recorrente categoria de Mittell (2006) -, tornando-se produtos culturais intensamente presentes também nos circuitos digitais de troca de arquivos e consumo online. 
A questão do desenvolvimento das formas narrativas contemporâneas está diretamente relacionada à emergência da televisão como espaço possível de qualidade artística e qualidade aqui entendida mais como discurso valorativo que característica ontológica -, e isso não pela superação do cinema como meio audiovisual artisticamente legitimado, mas pelo investimento na singularidade estilística das séries no panorama audiovisual de hoje.

A arte das séries de TV, como bem aponta Colonna (2010), estaria definida não unicamente pela contenção da linguagem e pelo investimento em mise-en-scène (categorias valorativas tipicamente cinematográficas), mas, sobretudo pelo texto, capaz de atrair a atenção do público em um meio de exibição, por excelência, dispersivo e cacofônico (o aparelho de TV ou mesmo a tela do computador, sem o efeito imersivo da sala escura de cinema e cada vez mais inserido em um ambiente multitarefas), e de provocar repetições estruturais que, no entanto, apresentam-se constantemente como novidade.

\begin{abstract}
A série de televisão repousa na repetição: retorno de personagens, de temas e de situações, redundância de diálogos e da banda sonora com a imagem, mas também de mecanismos narrativos baseados na reiteração como o gimmick ou o leitmotiv. Essa é a grande diferença em relação à ficção literária ou cinematográfica; é por isso também que ela substituiu o conto e o mito no imaginário popular (Ibid., p. 36).
\end{abstract}

No cenário teórico, em torno da questão formal das séries de TV, hoje em dia, é importante atentar para a transnacionalidade de perspectivas. No Reino Unido, as coletâneas organizadas por Gwenllian-Jones e Pearson (2004), Hammond e Mazdon (2005) e McCabe e Akass (2007) buscaram apontar para as transformações narrativas das ficções seriadas, tanto em seu viés de nicho a cabo, quanto na própria TV aberta, retomando conceitos como os de televisão cult e televisão de qualidade.

Na Espanha, a enorme coletânea organizada por Gómez (2011), de quase mil páginas, com artigos em três línguas (espanhol, inglês e italiano) possui análises conjunturais e estudos de casos realizados por pesquisadores de vários países sobre as séries norteamericanas de hoje. Da Itália, autores como Maio (2004), Montelone (2005) e Savorelli (2010) vêm investindo em estudos analíticos formais sobre séries consagradas como Buffy The Vampire Slayer e The X-Files, e sobre as transformações estilísticas em gêneros consagrados como a sitcom.

Em outras perspectivas, muitas vezes se procura indicar a excelência dos produtos norte-americanos diante dos exemplares nacionais - e aí, os franceses se destacam (JOST, 2012; EZQUENAZI, 2010; COLONNA, 2010; BUXTON, 2010), ao enfrentarem o preconceito da academia em relação às análises estéticas de televisão, principalmente da televisão norte-americana que, na última década, passou a ocupar de modo quase predatório o horário nobre da televisão francesa. São pesquisas que buscam entender as especificidades das séries no cenário contemporâneo, em especial a sua capacidade 
narrativa de propor, em diferentes chaves genéricas, novidades expressivas tanto temática quanto formalmente.

No Brasil, não podemos nos esquecer de obras fundamentais como Pallottini (2012), Machado (2000) e Balogh (2002), que ofereceram contribuições determinantes para o estudo dos formatos televisivos nacionais. O modelo televisivo tradicional é de matriz, sobretudo, nacional, cujos produtos ocupam, em termos de audiência, a maioria dos domicílios brasileiros. Por isso, também, a ênfase dada ao estudo do produto nacional (particularmente, a telenovela global) na nossa história teórica e crítica. Porém, com o aumento da presença das séries no espectro de nossa experiência televisiva - mediada fundamentalmente pela internet e pelos demais formatos digitais -, a investigação das diversas camadas que estruturam esse fenômeno se torna premente, visto a sua capacidade de engajar o público em experiências narrativas dentro e fora da rede, seja assistindo em streaming os momentos finais de Fringe, seja baixando a temporada única da hoje cult Freaks and Geeks, ou mesmo esbarrando em um episódio de The Walking Dead em uma terça-feira à noite na Band.

\section{Contexto tecnológico: o digital, a rede e uma cibertelefilia}

Como aponta Miller (2009), a televisão, em seu modelo tradicional, mesmo diante das transformações tecnológicas e culturais em curso, ainda é o meio de comunicação dominante nos Estados Unidos - e não seria equivocado dizer que também aqui no Brasil. Por isso mesmo, nosso objetivo neste artigo não é estabelecer quaisquer bases discursivas em favor de uma televisão nova, que estaria, a seu modo, superando uma maneira antiga e defasada de produzir e consumir TV.

Antes de tudo, queremos apontar para um conjunto de condições que, desde as últimas duas décadas, estabeleceram os alicerces para uma cultura das séries na contemporaneidade. A pergunta que nos interessa, nesse espectro, é a seguinte: de que modo as formas atuais de consumo televisivo em suporte digital (seja pela internet, via acesso legal ou ilegal, seja por DVD ou Blu-ray) têm criado as condições para a formação de uma nova telefilia, diacrônica e transnacional?

Nesse período, vimos se formar uma geração de espectadores capazes e interessados em assistir séries pela internet, através tanto de sistemas de transmissão em streaming, simultaneamente à exibição nos países de origem, quanto de download, via torrent, disponibilizados em sites e fóruns especializados. Além disso, circula na rede uma ampla gama de material exclusivo, oferecido pelos canais, e que vão desde promos, trailers e entrevistas, até expansões do mundo narrativo em websódios, blogs ou sites de personagens.

Junto a esse processo, vêm sendo desenvolvidas diversas estratégias para estimular o espectador a comentar nas redes sociais durante a exibição dos episódios, como a presença da hashtag da série no canto da tela, ou mesmo a participação de membros da equipe e dos atores comentando com os seguidores no Twitter sobre o desenrolar da narrativa. 
No contexto atual, o que garante a circulação de inúmeros exemplos de séries na internet não é somente a manutenção do seu arquivo em algum provedor específico ou a sua impressão em uma mídia física para ser adquirida em lojas do ramo, mas a constante troca desses arquivos pelos usuários, através de sistemas de armazenamento diversos, tanto em sites de hospedagem de vídeos, quanto através do compartilhamento peer to peer, com suas estratégias cada vez mais intrincadas de partilha de informação.

Desse modo, com a internet vamos gradativamente deixando de falar de exportação, para falar de circulação de produtos televisivos. Num primeiro momento, pode parecer a simples mudança de um paradigma industrial do capitalismo (com os bens materiais ocupando o grosso dos proventos) para um capitalismo pós-industrial, cognitivo, em que os bens simbólicos e culturais circulam transnacionalmente com mais fluidez, num circuito virtual extremamente complexo e intrincado. Não se pode adjurar aqui a superação - pelo menos não imediatamente, como os dados culturais e econômicos indicam de um modelo de televisão nacional e em fluxo, para um modelo transnacional e em rede.

Essa superação, se e quando ocorrer, será fruto de um longo e matizado processo de disputas materiais e simbólicas. No entanto, seria leviano ignorar que vivemos em um contexto cultural e tecnológico singular, em que a facilidade de acesso a diferentes séries, inclusive de épocas passadas, vislumbra a formação de um conjunto de novos espectadores cujo repertório está sendo formado por uma tela conectada, cujos hiperlinks apontam para um ambiente multitarefas e multiplataforma perante o qual redimensionamos nossa atenção e nossas funções espectatoriais.

A televisão brasileira a cabo, também a seu modo, busca estratégias para ocupar os espaços digitais de oferecimento de material televisivo. São os casos do Muu (da Globosat), do HBO Go e do Telecine Play, só para lembrar de alguns exemplos de disponibilização de repertório televisivo na rede pelos próprios canais. Eles demonstram o esforço que os conglomerados televisivos estão encampando para atender a essas novas demandas de consumo.

O cenário que o contexto atual projeta é de termos acesso pela internet, não somente aos programas que estão no ar de modo sincrônico, mas também e, cada vez mais, aos vídeos antigos, à memória dos canais, ao que nos afetara, quando mais jovens, e cujas imagens gostamos de recorrer vez ou outra. Uma telefilia de verdade só é possível diacronicamente, ela requer memória e acesso contínuo, com os quais podemos traçar a história dos gêneros e dos formatos, entender suas conformações e, porventura, suas superações. E é no universo do digital, dentro e fora da rede, que se armam os alicerces dessa espectatorialidade hiperconectada, típica de uma cultura das séries, que podemos chamar de cibertelefilia.

Isso significa que o interesse pelo universo das séries tem ampliado de modo considerável a oferta de material televisivo para além do que está sendo exibido sincronicamente, indo em direção a séries clássicas que agora podem ser revistas à luz dos interesses atuais. Os interessados em sitcom podem investir na história 
do gênero, comprando os DVDs de I Love Lucy, assistindo online episódios esparsos de The Honeymooners ou Blackadder, ou ainda baixando por torrent as temporadas de Fawlty Towers ou The Mary Tyler Moore Show.

Miller (2010, p. 142) comenta ainda que a sua, hoje, célebre pesquisa em torno do seriado britânico The Avengers foi realizada sem o autor ter disponível os episódios do programa, tendo ele que ir ao British Film Institute (BFI) para assistir aos episódios preservados, sempre que necessitava, para os fins de seus interesses analíticos. Hoje, todas as temporadas da série estão digitalizadas, à venda em DVD, e circulando na rede. A facilidade de acesso às obras, de hoje e de outrora, vem permitindo uma ampliação dos modos de assistir aos programas, seja nos próprios estudos acadêmicos, seja no envolvimento dos fãs com determinadas séries, gêneros e formatos. A digitalização desses programas, de modo diacrônico, demonstra o amplo circuito cultural em que as séries estão inseridas, a sua necessidade de permanecer vivas, em circulação, mesmo diante da efemeridade que sempre caracterizou a estrutura em fluxo do modelo televisivo tradicional.

\section{Modos de consumo: a emergência do fandom e o papel da crítica}

A relação entre as séries e seu público é o vértice derradeiro do esquema conceitual que criamos para entender a cultura das séries. Trata-se de novas e complexas dinâmicas espectatoriais que são gestadas no seio das comunidades de fãs, através de trocas simbólicas e materiais entre si, dos fãs para as emissoras e das emissoras para os fãs. É, de fato, um processo comunicacional muito complexo, que faz emergir o modo dialético e inter-relacionado por meio do qual se dão as relações entre a grande mídia e seu público.

Para cada série de televisão bem sucedida, há um sem número de comunidades virtuais que agregam os fãs, de diferentes localidades e matrizes culturais, em torno da troca de informações, experiências e outras práticas participativas, como a criação de fan-art, fanfiction e fanfilm, obras pictóricas, literárias e audiovisuais feitas e divulgadas pelos fãs. Com a facilidade de acesso propiciado pelo digital, que, além disso, permite assistir aos episódios para além do fluxo televisivo, os fãs passam a demonstrar um conhecimento amplo sobre os modos de encenação, os diálogos, a caracterização dos personagens, o desenvolvimento das tramas e a montagem das cenas.

Esse conhecimento se materializa em sites enciclopédicos específicos de cada série, como o célebre Lostpedia, lançado em 2005, por Kevin Croy, para servir como uma base de dados de informações sobre a série Lost, de livre acesso e atualizada e corrigida diretamente pelos próprios fãs. O Lostpedia é sem dúvida uma das principais fontes para qualquer pessoa interessada na série, por organizar as informações narrativas e contextuais sobre o que ocorrera na ilha, além de possuir referências de publicações acadêmicas e obras de fãs.

Nesse cenário, há diferentes maneiras de se garantir o engajamento do público com a série através da internet, o que permite Ross (2008, p. 6) dizer que "a experiência 
das pessoas em assistir e fazer televisão hoje é cada vez mais inseparável da teleparticipação (seja ela literal ou conceitual)". Segundo a autora, o que ela chama de teleparticipação é exatamente a atividade online de interagir com a TV, e ocorre através de estratégias de convite do próprio programa em direção a seu público.

Haveria, então, três tipos de estratégias de convite: o evidente, por meio da qual os produtores diretamente convidam o público a interagir (um exemplo é o já citado uso da hashtag do programa no canto da tela, para que o público comente no Twitter); o orgânico, em que não há o convite direto da emissora para a teleparticipação, mas em que a diegese dos programas incorpora a presença (material ou simbólica) da experiência participativa (um exemplo é a série britânica Sherlock, cujo blog do Dr. John Watson, por meio do qual o personagem escreve as histórias do detetive, surge nos episódios e existe de fato na página oficial da série).

Por fim, o obscuro, em que o convite se dá no interior da própria estrutura narrativa da série, de modo tão subliminar que só um espectador assíduo é capaz de decodificar. A série Arrested Development, em seus últimos momentos, costumava brincar com a baixa audiência e a possibilidade do cancelamento indicado pela Fox; em um episódio da terceira e última temporada, ela usa o duplo sentido do termo S.O.Bs (que comumente se refere a son of a bitch), indicando também o site criado pelos fãs para pressionar a emissora contra o cancelamento ${ }^{6}$.

Além desses modos de consumo e participação do público com os programas, cada vez mais intricados e polifônicos, é importante destacar que essa cultura das séries também se vale das atividades noticiosas e críticas, no sentido de haver espaços específicos para a divulgação e a análise dos programas, seja em veículos de comunicação de maior abrangência, seja em sites e blogs específicos sobre o tema.

De fato, uma pesquisa rápida sobre as séries nos principais jornais e revistas vai indicar a crescente quantidade de material, tanto noticioso quanto crítico, inclusive com espaços próprios dedicados ao fenômeno. No caso brasileiro, o jornal O Globo e a revista Veja disponibilizam em seus sites, páginas só sobre séries de TV, disponíveis também nas redes sociais. ${ }^{7}$ No caso da Veja, a jornalista Fernanda Furquim há pelo menos uma década e meia escreve e pesquisa sobre as séries, tendo inclusive criado a primeira revista exclusiva sobre o tema, a TV Séries, e lançado um dos únicos trabalhos nacionais sobre o gênero da sitcom (FURQUIM, 1999).

Além disso, há diversos sites criados e mantidos por fãs de séries, que servem tanto de espaço para se atualizar das notícias dos bastidores da produção, quanto para a análise de episódios específicos das séries mais populares. No Brasil, podemos citar, entre outros, os sites Ligado em Série, Séries News, Séries \& TV e Minha Série, ${ }^{8}$

6 Disponível em: <http://saveourbluths.com $>$.

7 Disponíveis em: <http://kogut.oglobo.globo.com/noticias-da-tv/series/ultimas-noticias.html $>$ e $<$ http://veja.abril. com.br/blog/temporadas/>, respectivamente.

8 Disponíveis em: <http://www.ligadoemserie.com.br/, http://seriesnews.com.br/>, <http://blogs.pop.com.br/tv/> e $<$ http://www.minhaserie.com.br/s, respectivamente. 
que oferecem sistematicamente notícias e opiniões sobre diversos programas. Na grande maioria dos casos, os criadores e mantenedores dos sites não trabalham diretamente com isso, nem mesmo são formados em jornalismo, rádio e TV ou estudos de mídia. São profissionais de outras áreas que em seu tempo livre escrevem e pesquisam sobre séries de TV, indo além de seu interesse específico por determinado programa, para escrever sobre as novidades dos canais, analisar episódios e premiações, repostar vídeos exclusivos e mesmo entrar em campanhas contra o cancelamento de determinada série. Desse modo, eles são parte fundamental do processo de produção, circulação e consumo de ficção televisiva que chamamos aqui de cultura das séries.

\section{Considerações finais}

Com a entrevista do CEO da Netflix, Reed Hastings, ao jornal Folha de São Paulo em janeiro deste ano, ${ }^{9}$ fica claro que o serviço de oferta de vídeo sob demanda está bastante atenta para o interesse do público que as emissoras não conseguem suprir. Sem qualquer pudor, ele revela que a pirataria (como a mídia oficial costuma se referir a qualquer tipo de circulação virtual de objetos culturais que não estejam sob a guarda dos direitos de autor) é sim um dos principais indicadores para o Netflix adquirir séries para o seu catálogo, ou mesmo para produzir seus próprios programas. Segundo Hastings, a partir daquilo que é mais baixado em serviços de troca de arquivos como o BitTorrent, a empresa se empenha em comprar os direitos de transmissão, não só para os Estados Unidos, mas para os demais países em que o serviço é oferecido.

Com isso, o Netflix busca fazer a ponte entre os interesses do público e seus programas ou gêneros de preferência. É novamente o caso de Arrested Development, que mais de meia década depois de seu cancelamento, teve uma nova temporada produzida pelo Netflix. A pergunta que fica é: por que uma nova temporada de uma série que foi cancelada por conta de sua baixa audiência na televisão? A resposta mais básica é a de que o Netflix sabe, através de seus sistemas de monitoramento do público, que boa parte da comunidade de fãs que se formou em torno de Arrested Development, o qual a considera cult até hoje, utiliza serviços de vídeo sob demanda. ${ }^{10}$ É, portanto, um público consumidor em potencial, e, como tal, pode ser atraído por algo que ninguém mais pode lhe dar: o retorno de sua série favorita.

Esse é só mais um caso dentro do complexo processo que envolve as séries de TV na contemporaneidade. Nosso objetivo neste artigo foi apresentar as condições que sustentam o cenário de investimento em novas formas narrativas, de complexificação do contexto tecnológico e de modos de consumo cada vez mais multifacetados. Na figura abaixo, procuramos sintetizar essas condições básicas, indicando através

9 Disponível em: <http://www1.folha.uol.com.br/tec/1220698-pirataria-de-filmes-e-termometro-para-formarcatalogo-diz-executivo-chefe-do-netflix.shtml>. Acesso em: maio 2013.

10 Sobre o modo como o Netflix usa os dados dos usuários para montar o seu catálogo, conferir: <http://www. salon.com/2013/02/01/how_netflix_is_turning_viewers_into_puppets/>. 
de vetores de duas vias que se trata de um processo dialético cujos termos em questão se inter-relacionam, influenciando uns aos outros sem ordem hierárquica preestabelecida.

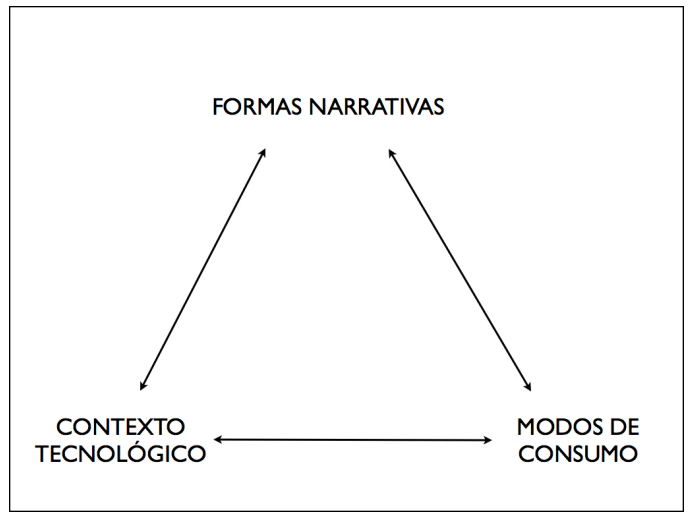

Fig1. Diagrama de vetores dos elementos constituintes de uma cultura das séries.

A cultura das séries é o resultado da intensa atuação desses vetores, definindo-se como um cenário cultural singular com suas próprias e específicas dinâmicas de produção, circulação e consumo. Mesmo se circunscrevendo a um universo audiovisual, sobretudo estrangeiro (e mais especificamente norte-americano), é fundamental aqui no Brasil que voltemos a atenção para essas dinâmicas, visto que elas estão presentes nas práticas culturais de inúmeras pessoas, influenciando novos roteiristas e diretores, tornando-se referência para nossos próprios programas. Por isso mesmo, este artigo propôs essas três condições centrais para o estudo da cultura das séries, que podem e devem ser discutidas e ampliadas em ulteriores debates teóricos e estudos de caso, de modo que a pesquisa acadêmica no país cada vez mais intensa e articuladamente possa ajudar no entendimento do fenômeno.

Marcel Vieira Barreto Silva é professor adjunto do curso de Cinema e Audiovisual da Universidade Federal da Paraíba.

marcelvbs@hotmail.com

\section{Referências}

BALOGH, A. M. O Discurso Ficcional na TV. São Paulo: Edusp, 2002.

BUXTON, D. Les Séries Televisées: Forme, Ideologie et Mode de Production. Paris: L'Harmattan, 2010.

CALABRESE, O. Los Replicantes. Anàlisi, Barcelona, n. 9, p. 71-90, 1984.

COLONNA, V. L’Art des Séries Télé: Ou Comment Surpasser Les Américains. Paris: Payot \& Rivages, 
2010.

EZQUENAZI, J. P. Les Séries Télévisées: L'avenir du cinéma? Paris: Armand Colin, 2010.

FURQUIM, F. Sitcom: Definição e História. Porto Alegre: FCF, 1999.

GÓMEZ, M. A. P. (org.). Previously On: Estudios Interdiscipinarios Sobre la Ficción Televisiva en la Tercera Edad de Oro de la Televisón. Sevilla: Biblioteca da la Facultad de Comunicación de la Universidad de Sevilla, 2011.

GWENLLIAN-JONES, S.; PEARSON, R. Cult Telvision. Minneapolis: University of Minnesota Press, 2004.

HAMMOND, M.; MAZDON, L. The Contemporary Television Series. Edinburgh: Edinburgh University Press, 2005.

HILMES, M. The Television History Book. Londres: BFI, 2002.

JOST, F. Do que as séries americanas são sintoma? Porto Alegre: Sulina, 2012.

LOPES, M. I. V. (org.). Telenovela: internacionalização e interculturalidade. São Paulo: Edições Loyola, 2004.

MACHADO, A. A Televisão levada a sério. São Paulo: Senac, 2000.

MAIO, B. Buffy The Vampire Slayer. Roma: Aracne Editrice, 2004.

MCCABE, J.; AKASS, K. Quality TV: Contemporary American Television and Beyond. Londres: I.B.Tauris, 2007.

MILLER, T. A Televisão Acabou, a Televisão Virou Coisa do Passado, a Televisão Já Era. In: FREIRE FILHO, J. (org.). A TV em Transição: Tendências de Programação no Brasil e no Mundo. Porto Alegre: Sulina, 2009, p. 09-25.

Television Studies: the basics. Nova lorque: Routledge, 2010.

MITTELL, J. Narrative complexity in contemporary american television. The velvet light trap. Austin: The University of Texas, n. 58, p. 29-40, 2006.

MONTELONE, F. Cult Series: Le Grandi Narrazioni Televisive nell'America di Fine Secolo. Roma: Dino Audiono Editore, 2005.

NOAM, E.; GERBARG, D. Introduction. In: NOAM, E.; GERBARG, D.; GROEBEL, J. Internet Television. Londres: Lawrence Erlbaum Associate Publishers, 2004.

PALLOTTINI, R. Dramaturgia de Televisão. 2 ed. São Paulo: Perspectiva, 2012.

PEARSON, R. The Writer/Producer in American Television. In: HAMMOND, M.; MAZDON, L. The Contemporary Television Series. Edinburgh: Edinburgh University Press, 2005, p. 11-26.

ROSS, S. M. Beyond the Box: Television and the Internet. Oxford: Blackwell Publishing, 2008.

SAVORELLI, A. Beyond Sitcom: New Directions in American Television Comedy. Londres: McFarland \& Company, 2010. 